\title{
Graduation-on-Time or a Daydream
}

KOME - An International Journal of Pure Communication Inquiry

Volume 6 Issue 2, p. 111-113.

(C) The Author(s) 2018

Reprints and Permission:

kome@komejournal.com

Published by the Hungarian Communication

Studies Association

DOI: 10.17646/KOME.75692.92

\section{Yasaman Parsia and Shahryar Sorooshian Universiti Malaysia Pahang, Faculty of Industrial Management, MALAYSIA}

The information presented on university websites is vital for candidates who are planning their studies. This letter tries to draw the readers' attention to the achievability of the minimum graduation time for postgraduate students.

Universities commonly compete to attract students. In achieving their goals of attracting student candidates to study at their respective universities, the process within some universities is to offer postgraduate study to candidates as soon as possible. The information that students might consider as valuable criteria when selecting a university may be the minimum period of study required to graduate. For instance, in a research-based field, a program where a full-time master's degree could be completed in one year and a doctorate degree could be completed in two years would be extremely attractive. Furthermore, it may be more attractive for universities to offer scholarship opportunities and postgraduate arrangements. Accordingly, each offer letter received alongside the information provided on the university's website would enable the candidate to make a decision and register. This would enable the candidates to plan their time, life, and finances for postgraduate education based on the advertised information (mostly from the university's website). The achievability of the minimum graduation time, especially for full-time research-mode studies is of significant concern and the reason for writing this letter.

One problem that can prolong the graduation process is due to the supervisors. Having more postgraduate students, in theory, could help to ease academic promotions and help achieve key performance indicators (KPIs). However, unprofessional professors may in some instances accept any research proposal during their evaluation of research applications, which may cause delays due to several reasons: (i) when, following registration, the supervisor/professor requests the student to rewrite or modify the research proposal based on the professor's expertise; (this might also be due to avoide producing fake graduates, or to screen out customers of scholarly-black-markets as discussed by Sorooshian (2017a, 2017b)) (ii) when the professor requests changes in the research, but he/she is unable to assist in the research study given that the scope does not match their area of expertise.

The next possible delay is the issue of accruing work. This is when the student needs his/her supervisor(s) to read and review the work, but that review is delayed for various reasons. Sometimes the professors are too busy to review and comment on the student's work quickly or within a reasonable amount of time, or it is only a cursory review, not detailed nor comprehensive and lacking comments. Therefore, the correction and resubmission will often consist of several rounds. 
Multilevel evaluations are another cause of delay where some faculties have more than one round in evaluating a thesis, proposal defense, colloquium seminar, comprehensive exam, data defense, Pre-Viva, and Viva Voce. The time before evaluations when examiners need to review the work could equally be a further delay, especially when students are asked to pass an evaluation before proceeding to the next step of the research. Notwithstanding, it becomes much worse when the selection of examiners is undertaken via a separate process. For instance, if a busy third person, for example, the Dean or Deputy Dean of the faculty is responsible for overseeing the selection process for examiners. In this case, the student's work is queued or put on hold until the third person can select an examiner. Then, the administration staff prepares the appointment letter for the examiners, signed by the Dean of the faculty along with the appointment letters whereby only then do the administration staff forward the student work to the examiners.

The authors have observed cases where the examiner (with the delay or without delay) declines the examination task due to their limited availability or by not matching the scope of work with their expertise. The examiner selection process continues and is repeated until the student's work can be examined. Following this stage in the review process by the examiner, it is then time to submit the work along with the corrections suggested by the examiners and seeking their approval which also takes some time if they need time to review the work again after the corrections have been made and before their endorsement.

Having the right examiner can be critical for no delays in graduation (Yahaghi et al., 2017), but sometimes due to the diversity of postgraduate research and the lack of expertise in some faculties, the faculty may ask a professor to evaluate a research which does not fit entirely with their expertise. Again, this may result in irrelevant comments being made during the evaluation process which could possibly mislead the student and cause delays in graduating. Finally, in some cases publishing articles in indexed journals or at conferences is among the requirements of graduation (multiple published articles may be required if students have received university scholarships); so publication requirements can also become obstacles and may cause delays.

Following the study registration, the student may wish to apply for the offered graduate-schemes or scholarships. If the student was successful in being awarded a scholarship from among the competition, and to obtain financial support, often the terms and conditions regarding the sponsorship are misleading and may equally cause delays in graduating. Although financial sponsorship is not the main reason for graduation delays, the terms and conditions that were not apparent nor revealed on the university website at the time of registering might cause delays in graduation; for example, teaching and working for the university. While somewhere on the website additional requirements may have mentioned, for example, eight hours teaching, the site likely never been mentioned the additional time that the student was required to spend in preparation of teaching, marking class assignments, etcetera. Another example could be regarding international students who planned to return to their home country to collect research data but are unable to leave the campus due to their weekly teaching responsibilities and commitments.

Notably, the duration presented by universities in some cases for the minimum graduation time is entirely different from what is observed in reality and is a marketing technique adopted by some universities to attract students. This miscommunication is an integrity issue for higher education. Universities should be encouraged to apply lean service/process models to minimize student wastage time, thereby helping universities to be seen as trustworthy and transparent organizations for students to progress their studies. Also, for university websites, presentation of statistical average and/or domain of actual graduation time for recently graduated students (for example, based on the data from the most recent graduation convocation) is encouraged to lessen the miscommunication issue. Similarly, an 
open-access forum on the university website could facilitate unfiltered communication between alumni, current postgraduate students, and postgraduate candidates, for example, to clarify the graduation delay sources, benefits of the reduction of website limitations and miscommunications. Additionally, as a recommendation, the Ministry of Education in each country should control via guidelines and policies all university websites to eliminate dishonest information and to ensure that all the displayed conditions are both feasible and practical.

\section{References:}

Sorooshian S. (2017a), Fake graduates, Science and Engineering Ethics, 23(3), 941-2. CrossRef

Sorooshian S. (2017b), Scholarly black market, Science and Engineering Ethics, 23(2), 6234. CrossRef

Yahaghi H, Sorooshian S, Yahaghi J. (2017), Viva delay, Science and Engineering Ethics, 23(3), 945-6. $\underline{\text { CrosRef }}$ 